\title{
Far from home, far from safe: state violence against unaccompanied refugee children seeking asylum in Kenya
}

\author{
ROSALIND RADDATZ \\ Faculty of Arts and Science, Aga Khan University, Nairobi, Kenya \\ MATTHEW KERBY \\ School of Politics and International Relations, Australian National University, \\ Canberra, Australia \\ matthew.kerby@anu.edu.au
}

MS received July 2019; revised MS received January 2020

\section{Introduction}

In 2015, after Al-Shabaab rebels broke into the house where Hani and four other girls were staying in rural Somalia and threatened to take them as camp wives, the girls decided to flee to Kenya. Only 13 years old, Hani was now a refugee. Days later, before Hani and her roommates reached the Kenyan border, they were captured by another group of Al-Shabaab rebels, who gang raped them repeatedly and restrained them with ropes. When the men left them alone one night, Hani was able to help untie her companions and they made their way to the border town of Liboi, where they caught a bus to the coastal city of Mombasa.

Hani's troubles did not end when she reached Kenya. In Mombasa, Hani struggled to survive and soon discovered she was pregnant from being raped. Since 2014, the Kenyan government had redoubled its efforts to forcibly detain, deport or encamp its refugee population after two gunmen opened fire in a Mombasa church, killing six worshippers. Nearly all arrests targeted Somali nationals living in urban areas. As a result, Hani lived in constant fear of the authorities.

Children without the protection of a parent or adult, like Hani, are arguably the most vulnerable group of refugees. From the time she arrived in Mombasa, Hani experienced near-daily intimidation and harassment from Kenyan security forces. Ultimately, she miscarried before she reached term. Like many other Somalis in Kenya at the time, Hani was arrested for having no official documentation and detained in prison. There, she was interrogated and accused of being a member of Al-Shabaab and a would-be terrorist. 


\section{Rosalind Raddatz and Matthew Kerby}

Caught up in the conflicts of East Africa, refugees leave their countries of origin and head to the closest place of peace. Like Hani, who notes, 'I wanted to be safe away from the trauma of war', since the 1990s, hundreds of thousands of refugees have sought security in Kenya. It is ironic then that so many of the region's refugees experience violence anew in their host country, often at the very hands of those entrusted to protect them.

The research conducted for this article addresses an existing lacuna in the academic literature on unaccompanied refugee children. Specifically, it considers the issue of violence perpetuated by state security forces on unaccompanied refugee minors living in Nairobi. While substantial literature exists on the subject of refugees in Kenya, this study complements existing research on violence and refugees in terms of the class of refugee (unaccompanied refugee minors), as well as the data employed: a unique survey of refugee children. Our unique data set indicates widespread violence among refugee children living in Nairobi and denotes the prevalence of several kinds of violence in particular. This article provides a first exploration of this data set to ascertain child refugees' experiences with state violence.

\section{Security Policy and Practice towards Refugees Living in Nairobi}

In practice, if not by law, for nearly three decades, the Kenyan government has required refugees to reside in one of five camps, which are home to 86 per cent of Kenya's refugees (O'Callaghan and Sturge 2018). The United Nations High Commission for Refugees (UNHCR) has supported the government's encampment practices by requiring refugees to reside in camps unless they meet one or more 'encampment policy' exceptions, such as needing specialized medical care, or pursuing further education, or they are at an elevated security risk in the camps (Parker 2002). Exceptions are difficult to meet, but living conditions in the camps are exceedingly harsh. In addition to desert climate conditions, refugees living in Kenya's camps frequently experience security threats, find it hard to access education and medical assistance, and have few opportunities to generate an income. Violence in the camps is commonplace and women are at high risk of sexual violence. For all the barriers, numerous refugees still seek to relocate to Kenya's urban centres, including Mombasa, Kisumu, Kisii and Nakuru, but most of all Nairobi.

The size of Nairobi's refugee population is not known. According to the UNHCR, in 2017, 61819 registered refugees lived in the capital city, but the true number is thought to be nearly triple that. For the high number of refugees known to be in Nairobi, there is little demographic data available on this population. Urban refugees seek anonymity by staying mobile, almost all work in the informal economy and most eschew modest UN support for fear of being sent to one of the camps or forcibly deported. Consequently, urban refugees are a largely hidden population (Parker 2002). While children are thought to comprise up to a third of Nairobi's refugee population, there is virtually no data on them 
whatsoever. Of an already vulnerable group, refugee children are particularly defenceless, their experiences unknown and invisible.

Kenya has had a mercurial relationship with refugees since the 1970s, when thousands of Ugandans, fleeing Idi Amin's dictatorship, poured over the border into Kenya. However, it is mostly in the last decade that Kenya's state security forces (state police, the military and other ancillary forces created by the government) have come to target refugees. Kenya has been the site of numerous violent attacks, many of which have been perpetuated by Al-Shabaab, a Somali-based militia. After the Kenyan military deployed into Somalia in 2011, Al-Shabab mounted increasingly bloody and well-publicized attacks in Kenya, ostensibly to avenge atrocities committed by Kenyan armed forces while in Somalia. In 2013, the group attacked the prominent Westgate shopping mall in Nairobi, killing 62 civilians. Other attacks followed, including one on Garissa University in 2015, where 148 people on campus near the Somali border were killed. Most recently, in January 2019, Al-Shabaab mounted another Nairobi-based attack on the upscale DusitD2 complex, during which 21 civilians were killed.

The Kenyan government responded to the attacks by portraying Somali refugees as harbingers of terrorism and ordered a string of repressive measures aimed at curtailing refugee movement. In December 2012, the Department of Refugees announced an end to all refugee support activities in Nairobi, stating that all refugees in urban areas would be relocated to the camps. The order was overturned by the High Court in 2013, but not before thousands of refugees were rounded up and detained.

Throughout, government, media and citizens' attitudes towards refugees were consistently negative, with discourse on refugees linking them to crime, illegal activities, insecurity and, increasingly, terrorism (O'Callaghan and Sturge 2018). Unsurprisingly then, with each subsequent terrorist attack on Kenyan soil, violence perpetuated against refugees by the state increased. Meanwhile, the state's actions drew little to no public criticism. In the aftermath of such attacks, feeling compelled to show evidence of leadership and control, governments often choose to target certain groups for political gain and expedience. Refugees are particularly enticing; they have no electoral rights and domestic intolerance of foreigners is frequently high in times of crisis (Savun and Gineste 2019). This creates a ripe environment for state brutality without consequence.

Kenyan state oppression of refugees, particularly those of Somali origin, goes back nearly two decades. In 2009, the Ministry of State for Immigration and Registration of Persons claimed Somali refugees in Kenya created 'a major terrorism threat', noting that 'extremist groups' and 'Islamic radicals may use refugee flow to smuggle weapons and people into Kenya to engage in terrorist attacks' (MIRP 2009, in O'Callaghan and Sturge 2018: 15). Although Al-Shabaab is known to be active in the Dadaab camps (Burns 2010), there is scant evidence that refugees in Kenya have perpetrated acts of terrorism. All the same, in Kenya, Al-Shabaab, Somali refugees and terrorist violence have become conflated.

Limited Kenyan state capacity further exacerbates the victimization of refugees. Many of the world's refugees are hosted in developing countries with unstable 


\section{Rosalind Raddatz and Matthew Kerby}

institutions (Sy 2017). Research indicates that refugees can 'overwhelm a state's capacity to provide public services and can lead to conflicts over resources' (Adamson 2006: 176).

In the 1970s and 80s, refugees seeking haven in Kenya were able to self-settle. The onset of conflict in Sudan and Somalia in the early 1990s resulted in mass displacement and led to a influx of refugees into Kenya. In 1992 alone, the number of refugees streaming into Kenya spiked from 132000 to 400000 (Awuku 1995). In an effort to provide humanitarian assistance, while also seeking to control its insecure borders and manage the inpouring of foreigners, Kenya moved to contain refugees within two sites (Crisp 2000). Kakuma refugee camp is located in the Turkana district of Northwest Kenya, while Dadaab is located near the Somali frontier in the North East Province (NEP). Both locations are among the poorest and most politically marginalized in Kenya and feature frequent ethnic, economic and political conflict (Burns 2010).

Site of the Kakuma camp, Turkana is mostly a remote desert, with a small population, a stagnant economy, commonly besieged by famines and droughts. The indigenous Turkana people are nomadic pastoralists who depend on cattle for their economic survival; most live in abject poverty, with virtually no government social services (Aukot 2003). Seeing the humanitarian assistance meted out to the camp's refugees, the Turkana perceive themselves as unfairly disadvantaged and are threatened by Kakuma camp's inhabitants, with whom they have clashed often. Until recently, the four camps of Dadaab formed the largest refugee complex in the world, housing over 400000 people at its zenith in 2011 (United Nations High Commissioner for Refugees 2012). Like Turkana, Kenya's NEP features a small local population, limited economic opportunities and widespread poverty (Institut de Relations Internationales et Stratégiques, 2015).

Many Kenyans, including those in government, believe that refugees are one burden too many. Refugees are perceived as a financial strain on the Kenyan state and are seen by citizens as competing for limited resources. In both Turkana and NEP, wood is scarce and refugees' use of this material for makeshift shelters has contributed to widespread deforestation (Jacobsen 1997). Likewise, food insecurity is also blamed on refugees. Kenya's nomadic pastoralists require pasture and water for their livestock; in areas like Kakuma and along the Tana River (near Dadaab), large swaths of land have been destroyed by erosion, caused in large part by the presence of refugees. The draw of refugees on state resources generates a cost that 'falls disproportionately on nations least able to afford it, where the presence of large impoverished refugee populations further strains resources and perpetuates to poverty of the host nation' (Dowty and Loescher 1996: 47).

Kenya may be relatively more stable, powerful and prosperous than neighbouring East African countries, but this does not mean that it possesses the necessary resources to provide consistent support to its many asylum seekers. Large parts of the country experience ongoing food scarcity and severe drought. In September 2009, a grave drought in the North East resulted in famine, with 4 million Kenyan citizens seeking emergency food assistance from the World Food Program (BBC 2009; Rice 2009). Kenya also has at least 10000 of its own internally displaced 
persons living precariously, from electoral violence in 2007-08 and 2017, resource conflicts, inter-communal violence and Al-Shabaab attacks in 2017 and 2018 (Internal Displacement Monitoring Centre 2018).

In short, large numbers of refugees need food, water, fuel and shelter; Kenya is ill-equipped to provide these even to its own citizens. Refugee populations create social and economic pressures that developing states are unable (and frequently unwilling) to address and avert (Böhmelt et al. 2019). Consequently, many Kenyans do not believe that they can (or should) help refugees when the state cannot adequately meet the needs of its own citizens.

Terrorist attacks already give Kenya's security forces ample justification to target refugees. The added economic and social pressures that stem from hosting large numbers of refugees only give the state more justification to target the same population it perceives as the source of many of its ills. Kenya's security responses, particularly towards refugee Muslims and Somalis, have grown harsher over time. Following the Westgate attack, in 2014, the government launched Operation Usalama Watch, during which more than 6000 police and military were deployed into Eastleigh, the Nairobi neighbourhood where most Somalis live (The Star 2014). In less than a month, nearly 3000 residents had been rounded up and detained at the Kasarani football stadium, with 481 deported, mostly to Somalia (Balakian 2016). Two years later, in 2016, Kenyan officials publicly announced the closure of the three Dadaab camps within 6 months, claiming they were 'a breeding ground for terrorists' (Muraya 2016).

Racialized political rhetoric, state scapegoating, compounded by ruthless police round-ups and a government with little capacity to cater to vast numbers of displaced people have left many refugees, especially Somalis, feeling marginalized and unfairly discriminated against. Refugees continue to be regularly harassed and subject to extortion by the Kenya police. Many experience frequent verbal, physical and sexual abuse by the police and other Kenyan authorities. Somali and Ethiopian refugees living in Eastleigh, in particular, are targeted; many are stopped on a near-daily basis and threatened with deportation.

\section{Vulnerability of Minor Refugees}

There is no population more vulnerable than child refugees. Nearly all have witnessed horrific trauma; many have experienced great suffering first-hand. Alone, without the protection of an adult, refugee minors are at grave risk of violence during flight. Once they have arrived in a host country, they continue to be at risk. As a result of the traumas they encounter in flight, many child refugees continue to experience significant psychological challenges in the long term (Trang and Lau 2002).

There is a significant correlation between violence and child migration (Wong 2014; Clemens 2017). Numerous reports highlight the many kinds of violence that can trigger migration among minors, including death, torture, sexual assault, abduction and injury (Human Rights Watch 2015; United Nations High Commissioner for Refugees 2016; UK Amnesty International 2018). When 


\section{Rosalind Raddatz and Matthew Kerby}

violence, be it from non-state armed actors, their own families or government authorities, becomes so commonplace as to permeate all of a child's activities, many will flee their countries of origin to escape the violence that permeates their lives (Kennedy 2014; UNHCR 2014a). However, even as they travel to safe haven, children experience violence along the way, from human smugglers, militarized borders and discriminatory immigration policies (Aiken et al. 2014; Human Rights Watch 2015).

The migration journeys of children are fraught with violence, further demonstrating their vulnerability. A few children with the means may fly to a border town, purchase forged documents and hire a smuggler to cross the border, while the majority use other means, namely car, truck, train and walking (Swanson and Torres 2016). Unaccompanied children with no documentation are at particular risk of violence, especially by human smugglers and distance truck drivers - a primary means of child-refugee transportation in sub-Saharan Africa.

The disadvantages and violence an unaccompanied child encounters at every stage of migration - prior to flight (pre-migration), during the journey (migration) and on arrival in a host country (post-migration) - are cumulative stressors (Ko and Perreira 2010; Menjívar and Perreira, 2019). The recurring violence and hardship that many child refugees witness and experience while in transit put them at risk of long-term mental health difficulties (UNHCR 2016).

\section{Hypotheses}

Urban refugees in Kenya face distinct challenges in their interaction with state authorities. Recognizing that adult refugees living in Nairobi experience high levels of violence at the hands of security officials, we expected that refugee children would have a significant likelihood of encountering such violence as well. The literature indicates that Somali refugees are especially targeted by state officials. Similarly, we expected that Somali children would also have a higher likelihood of such violence. Refugee men and women are frequent targets of violence by state officials; we anticipated that refugee boys and girls would also experience a significant likelihood of violence by state officials. Considering that adult refugees frequently experience state violence, we expected that refugee children would also tell of difficulties with Kenyan state forces. Consequently, this article tests three hypotheses: one pertaining to country of origin, another according to sex and the last according to age. These hypotheses were selected because of our interest in assessing demographic determinants of experiencing violence as well the availability of data provided by the survey instrument.

\section{Country of Origin}

State violence towards refugees is widely tolerated; many Kenyans and Somali refugees are specifically targeted. While academic literature on Somali child refugees in Kenya is small, this is not to say that the Somali refugee experience is undocumented. Indeed, the public-health literature on Somali refugees is 
expansive (see Horn 2010; Ope et al. 2017; Gee et al., 2019; Im et al. 2019; Masters et al. 2019; for just a recent sampling). We are also know from NGO reports, the mainstream media, as well as the academic literature that Somalis are particularly targeted with violence (Gettlemen 2012; Sohns 2016; O'Callaghan and Sturge 2018; Scharrer 2018) and state-based violence in particular (Human Rights Watch 2010). Consequently, we expect this relationship to hold for children as well as adults. Moreover, we expect the likelihood of experiencing state violence to be higher for Somali children than children from other ethnic groups.

$\mathbf{H}_{\mathbf{1}}$ : Country of origin: Of Kenya's refugees, Somalis report being the targets of state security violence the most. Likewise, we expect to find that Somali child refugees will experience a greater likelihood of state violence.

Sex

Gender inequality is widespread in the countries of the Horn of Africa and East Africa. This disparity is exacerbated by a wide range of social and economic factors. While the negative effects of patriarchy and class are felt by girls regardless of their citizenship, the effects on unaccompanied refugee girls are particularly felt given their lack of legal status and family/community support networks, which in turn renders them especially vulnerable.

In this case, there may be reason to believe that girls and women experience higher levels of violence overall. But, with respect to violence at the hands of state officials, there is no reason (for or against) to believe that this relationship should hold when the perpetrator of violence (sexual and gender-based violence (SGBV) or not) is a police officer or border guard. Indeed, Human Rights Watch (HRW) reports that both male and female refugees described experiencing violence by Kenyan police (2010).

There is no question that male and female refugees experience different kinds of violence: women are more likely to experience SGBV; male refugees report violence that is typically physical in nature. However, it is worth noting that we do not distinguish between the different types or levels of violence experienced by refugee children. Further, we do not want to over-extrapolate from the 2010 HRW report given that the interview respondents were over 18 years old and resident in refugee camps while the subjects of this analysis are children and living in urban areas, outside the refugee camps. We also note that descriptions of violence perpetuated against minors (typically SGBV against girls) in the HRW report was attributed to other refugees in the camps and not against the police.

$\mathbf{H}_{2}$ : Gender: Both male and female refugees experience high levels of violence. We predict that boys and girls are equally likely to experience violence at the hands of state officials.

The violence that adult refugees residing in Kenya frequently experience, including at the hands of state officials, is widely documented. Refugees report being targeted because they lack official documentation (Balakian 2016) or they 


\section{Rosalind Raddatz and Matthew Kerby}

lack the financial means to pay bribes (Yusef 2014) or simply because they are perceived as taking resources that should first go to Kenyan citizens (Kumssa et al. 2014). As we undertook our research, we expected that refugee children residing in Nairobi would also tell of having experienced violence, including by state officials.

A refugee is considered to be a minor if they are under the age of 18 . However, there is a marked difference in the appearance of a very young child, below the age of puberty, and an adolescent. Compared with population ratios in the camps, where women and children form the majority, there are fewer refugee women and very young children living in urban areas. While there are exceptions, most unaccompanied refugee minors are over the age of 12 . As a result, it is more likely that older refugee children are more visible in the community, usually attempting to earn an income as part of the informal economy. Indeed, interview data collected for this research suggests that, of those refugee minors living in the city, girls are more likely to find shelter and informal employment in the domestic sphere, while boys more often seek and find work as casual labourers.

Even during times of heightened alert, namely after terrorist attacks, state officials typically do not break into individual dwellings of refugees. Instead, they patrol the streets of neighbourhoods where refugees are known to reside and work. When state forces apprehend a refugee near or at their abode, it is usually outside on the street or alley, when the refugee is coming home.

$\mathbf{H}_{3}$ : Age: Our data indicates that the majority of refugee children experience violence in their host country. However, older children look and act more like adults. Consequently, we anticipate that a child's likelihood of experiencing state violence will increase with age.

\section{Data and Methods}

If urban refugees are already a little-studied population, less still is known about unaccompanied refugee children. The extant literature on refugee minors typically focuses on health, education and integration issues (Jakobsen et al. 2017; Oppedal et al. 2017; Plener et al. 2017; Keles et al. 2018; O'Higgins et al. 2018; Jensen et al. 2019; Majumder et al. 2019; Sierau et al. 2019). Far less is known about the determinates of violence directed towards unaccompanied refugee minors.

In this research, our inferences are derived from data collected to ascertain the prevalence of violence experienced by urban refugee children living in Nairobi, Kenya. This data is drawn from a survey undertaken in collaboration with Heshima Kenya (rebranded as RefuSHE in 2018), a Nairobi-based, non-governmental organization founded in 2008 that provides sanctuary, educational support and vocational training to refugee girls fleeing conflict and persecution from neighbouring East African countries. RefuSHE undertook a verification exercise on behalf of the UNHCR, in the first half of 2017. This exercise identified 943 unaccompanied and separated refugee children living in Nairobi (UNHCR 2017a). Although there are fewer minor refugee children living in urban areas 
of Kenya compared with the camps, the unofficial or real number of refugee minors living in Nairobi is believed to be much higher. In 2014, a third of registered refugees living in Nairobi were children (UNHCR 2014), whereas, outside of the city, children made up 56 per cent of the refugee population (UNHCR 2017a, 2017b). This indicates that, proportionally, there are fewer refugee children living in Nairobi and the population of urban refugees is generally older than those living in the camps (O'Callaghan and Sturge 2018). These figures also indicate that the number of children registered as part of the 2017 verification exercise is gravely low when compared to the population as a whole.

Three hundred and seventy unaccompanied and separated refugee minors living in Nairobi were selected from Heshima Kenya's Child Protection database, which was created as part of the UNHCR verification exercise. The database contains the contact details of refugee children registered with the UNHCR. The survey contains 15 questions that are divided into four categories: the background of the child; the living/care arrangements for the child; the prevalence of violence; and support networks. The violence variables are the primary variables of interest for this research. Respondents were initially asked whether they had experienced violence and, if they answered 'yes', they were posed a series of followup questions pertaining to the nature of the violence experienced and the context in which it was experienced. A copy of the survey instrument is available in the online supplementary appendix.

Table 1 provides summary statistics for the independent and dependent variables employed in this analysis. Immediately apparent elements include the neargender parity of the respondents, modal proportion of respondents who fall in the 14- to 17-year-old age category, the high proportion of refugees from the Democratic Republic of Congo (DRC) and, finally, the statistic that 64 per cent of the respondents have experienced some form of violence since arriving in Nairobi. The high number of respondents from the DRC reflects a surge of Congolese refugees to Nairobi following the 2017 massacres in the Central Kasai Region. To account for the imbalance in the sample, we estimate our models with population weights generated by country-of-origin statistics provided by the UNHCR.

However, when the violence variable is broken up into its constituent units, we find considerable variation among the categories Figure 1. Specifically, we find that state violence, child labour and slavery comprise the three most common forms of violence experienced by refugee minors. This is followed by sexual harassment, sexual violence, begging, attempted sexual assault and female genital mutilation. The less-reported forms of violence include survival sex, forced marriage, partner violence, sexual violence, sex work, sex slavery and pornographic exploitation. The categories are not mutually exclusive and individual refugees reported having experienced multiple forms of violence on multiple occasions. Consequently, there are more responses than there are respondents; this is a feature of the data that will affect the choice of our methods below. 


\section{Rosalind Raddatz and Matthew Kerby}

Table 1

\section{Summary Statistics}

\begin{tabular}{llllll}
\hline & Obs. & Mean & Std. dev. & Min. & Max. \\
\hline Female & 370 & 0.522 & 0.500 & 0 & 1 \\
Age $=8-10$ & 370 & 0.081 & 0.273 & 0 & 1 \\
Age $=11-13$ & 370 & 0.197 & 0.398 & 0 & 1 \\
Age $=14-17$ & 370 & 0.722 & 0.449 & 0 & 1 \\
Somalia & 370 & 0.211 & 0.408 & 0 & 1 \\
Ethiopia & 370 & 0.076 & 0.265 & 0 & 1 \\
DRC & 370 & 0.586 & 0.493 & 0 & 1 \\
Rwanda & 370 & 0.005 & 0.073 & 0 & 1 \\
Burundi & 370 & 0.054 & 0.226 & 0 & 1 \\
South Sudan & 370 & 0.062 & 0.242 & 0 & 1 \\
Saudi Arabia & 370 & 0.005 & 0.073 & 0 & 1 \\
Any abuse & 370 & 0.641 & 0.480 & 0 & 1 \\
State violence & 370 & 0.235 & 0.425 & 0 & 1 \\
\hline
\end{tabular}

(a)

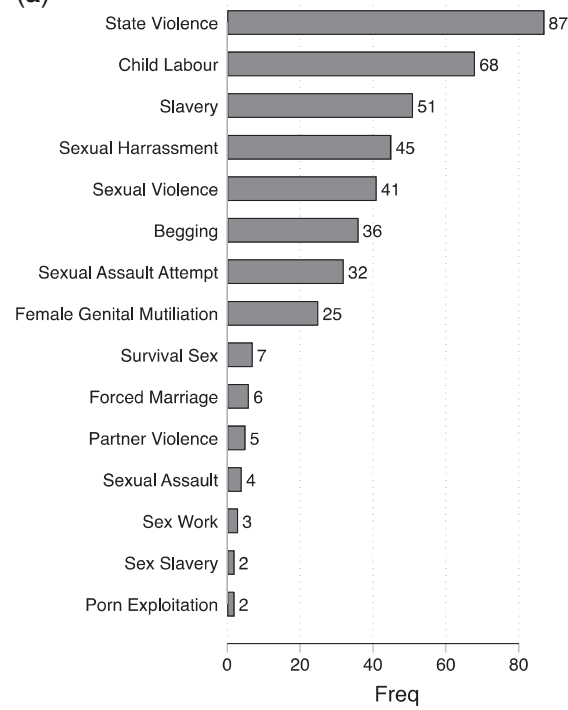

(b)

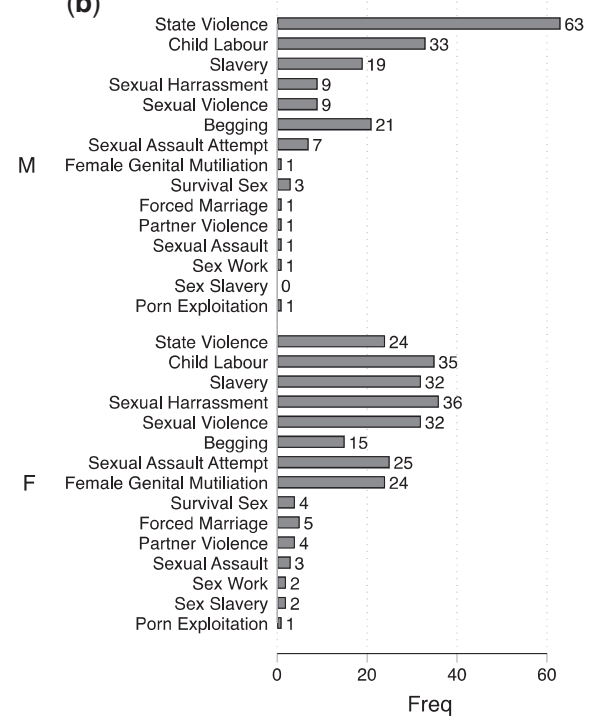

Figure 1.

Type of Violence.

\section{State Violence}

State violence is the modal category of violence experienced by children in our data set. We find 87 refugee children (23 per cent of the sample) reported having experienced some kind of violence or abuse at the hands of state officials. When assessing 


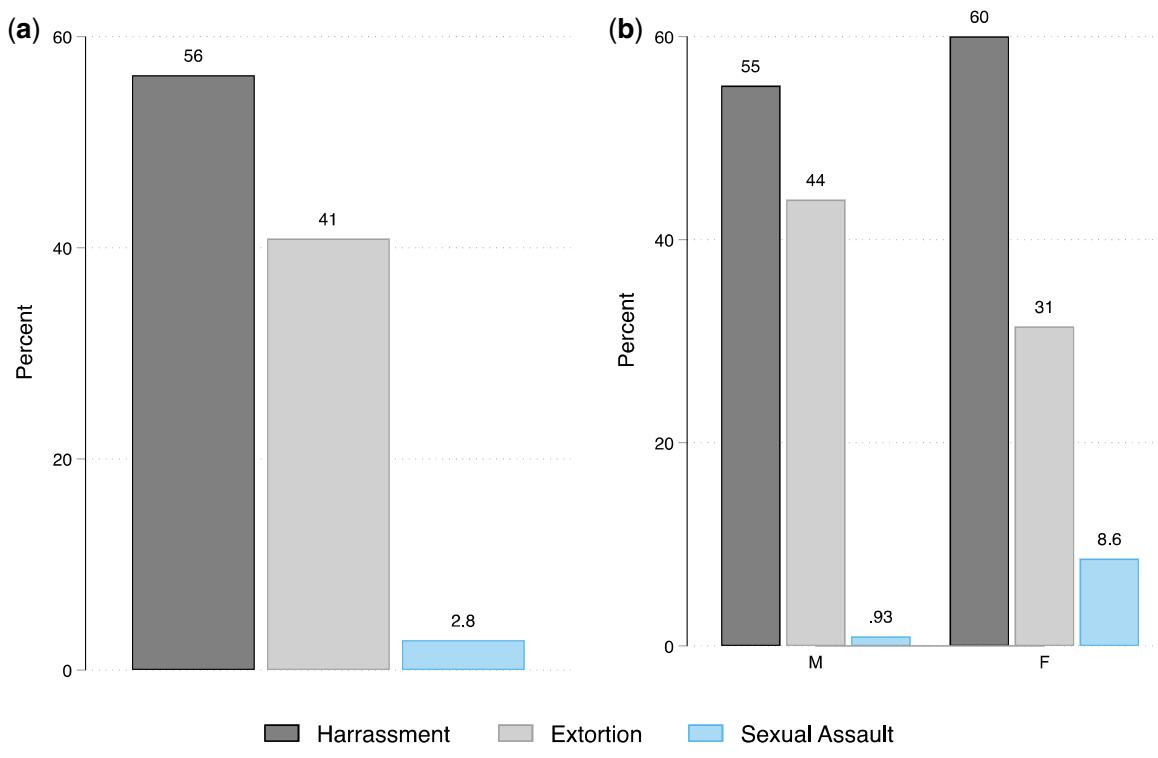

Figure 2.

\section{State Violence, Subcategories.}

refugees who experienced state violence, the $n$ is reduced to 234 due to respondents who answered 'N/A' to the 'Have you experienced state violence?' question.

Respondents who reported having experienced state violence were asked three follow-up questions in order to ascertain the type of violence they experienced. The three subcategories of state violence are harassment, extortion/bribery and sexual assault. Our data reveals that harassment is the most common form of state violence experienced by child refugees in Nairobi (Figure 2). Harassment consists of behaviour that demeans, intimidates, humiliates or embarrasses a person; the behaviour is perceived as threatening or distressing to the recipient. The forms of harassment that law-enforcement officers use to harass refugees include, but are not limited to, excessive force, threats, coercion, racial profiling and other forms of discrimination on the basis of the person's race, ethnicity, sexuality or religion. Harassment is followed by bribery/extortion. Only a very small proportion of refugee children reported having been sexually assaulted. In our survey, reports of sexual violence are so low that they render any inferences statistically and substantively insignificant. However, according to a large body of qualitative evidence, we know that a large majority of refugee children, particularly girls, experience sexual violence, both in their countries of origin as well as in the host country.

\section{Results}

We begin our analysis with a series of bivariate tabular analyses that assess the relationships between the independent variables set out in our hypotheses 


\section{Rosalind Raddatz and Matthew Kerby}

(country of origin, sex and age) and the dependent variables (state violence in general and three different types of state violence). The bivariate analysis is followed by a multivariate analysis using logistic regression.

\section{Country of Origin}

When we examine the levels of state violence experienced by refugee minors according to their country of origin, a number of features stand out (Figure 3). With two glaring exceptions - Somalia and Ethiopia - refugee children reported experiencing relatively low levels of state violence. However, Figure 3 shows that roughly half of Somali refugee children experienced state violence. However, fully 80 per cent of Ethiopian refugee children reported having experienced violence by state officials. Ethiopian refugees' experience is effectively reversed for refugees from the DRC, of whom only 26 per cent reported having experienced state violence. With respect to the remaining countries where the $n$ is less than 20, 44 per cent of Burundian refugees $(N=16)$ reported being the victims of state violence, 15 per cent of South Sudanese $(N=13)$ and 50 per cent of Saudi Arabians $(N=2)$. The differences across the categories is statistically significant at the 0.05 level. Finally, refugee children from Rwanda and Saudi Arabia experienced the least amount of state violence in the sample. This is due to the low number of respondents from these countries: two from Rwanda and two from Saudi Arabia.

Turning to the individual categories of state violence, only the extortion model proved to be statistically significant at the 0.05 level. The null hypothesis that there

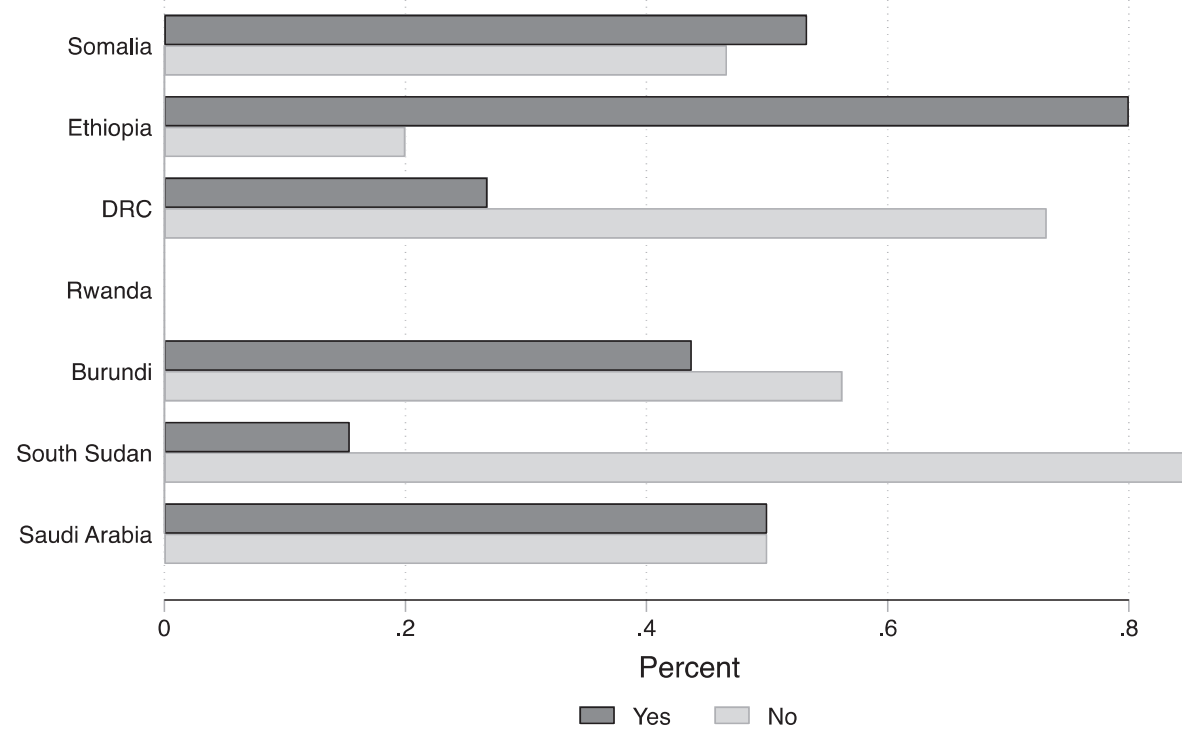

Figure 3.

State Violence, by Country of Origin. 
is no difference across countries with respect to the levels of harassment and sexual violence could not be rejected due to the low frequencies reported across cases. However, we do note that the reported frequencies are 'lopsided' in favour of reporting violence over not reporting violence.

\section{Sex}

Contrary to expectation, the results of our bivariate analysis reveal that refugee boys report higher levels of state violence than refugee girls (Figure 2a). This difference is statistically significant at the 0.05 level. With respect to the separate types of state violence (Figure 2b), we find no statistically significant difference between boys and girls when it comes to the levels of harassment experienced at the hands of state officials. However, we do find that boys report higher levels of having been the victims of extortion than girls and, perhaps unsurprisingly, girls report higher levels of sexual violence. The difference in the levels of extortion and sexual violence for boys and girls is statistically significant at the 0.05 level.

\section{Age}

Finally, the bivariate analysis for the age variable confirms our initial expectation that older children are more susceptible to experiencing state violence than younger children. Forty per cent of children aged 14-17 years reported having experienced state violence compared to 15 per cent and 23 per cent for 8- to 10-year-olds and 11to 13-year-olds, respectively. The differences are statistically significant at the 0.05 level. We find no statistically significant differences between the different age groups and the subcategories of state violence. This is due to the low frequencies recorded in the majority of the levels for each of the independent variables.

\section{Multivariate Analysis}

We undertook a multivariate analysis to further test our hypotheses regarding the predictors of violence against refugee children in general, and state violence in particular, by estimating two logistic-regression models. The first two models estimate the likelihood of experiencing any kind of violence as described in the survey, as well as the likelihood of experiencing state violence conditional on the demographic features outlined in the 'Data and Methods' section. The second series of models estimate individual logistic regressions for each of the subcategories of state violence. While it is tempting to estimate a single multinomial logistic model, we avoid this option; the nature of survey responses permits respondents to answer 'yes' to having experienced multiple forms of violence. The response categories for the dependent variable are therefore not independent (a requirement for multinomial logistic regression). Thus, we resort to individual models for each class of state violence. Logistic regression was chosen over a classical linear regression (OLS) due to the dichotomous structure of the dependent variable (i.e. experienced violence: yes/no). In addition to the odds ratios, for 


\section{Rosalind Raddatz and Matthew Kerby}

easier interpretation, we also present marginal effects for each of the statistically significant variables in the models.

When we assess the hypotheses in the 'any violence' model (Table 2, specification 1), we are unable to reject the null hypotheses for the country of origin and sex hypotheses. We were unable to find sufficient evidence to suggest that the likelihood of experiencing any kind of violence was significantly different, conditional on the country of origin or sex of respondent. However, and with respect to the age hypothesis, we found that the coefficients and corresponding odds ratios for children aged 14-18 years were positive and statistically significant at the 0.05 level. Specifically, refugee children between the ages of 14 and 18 years have odds of experiencing any kind of violence that are 3.24 the odds of refugee children who are between the ages of 8 and 10 years. The coefficients generated by a logistic regression have little meaning on their own apart from the direction of the effect. We therefore exponentiate the coefficients to create odds ratios. An odds ratio of 1 is interpreted as equivalence in the odds for two categories when interpreting the effect of a dummy variable or between a category and the reference category in a factor variable. Thus, an odds ratio of 0.5 for a dichotomous sex variable (female $=1$ ) can be interpreted as females have the odds of men of experiencing the event specified in the dependent variable (the likelihood of experiencing violence). Odds ratios for continuous variables are interpreted as a 1-unit increase in the variables value having a corresponding increase or decrease in the odds of experiencing the event. So, in effect, these children have odds of experiencing violence that are 224 per cent greater than the children in the reference category.

The second model (Table 2, specification 2), which examines the likelihood of experiencing state violence, appears more promising. Five of the seven covariates are statistically significant at the 0.05 level. With respect to hypothesis 1 , all country-of-origin levels are statistically significant at the .05 level. Relative to the baseline category of Ethiopia, and in descending order, we find that Somali refugee children have 0.21 the odds of experiencing state violence than those of Ethiopians, Burundians have an odds ratio of 0.12 , Congolese 0.06 and South Sudanese 0.04. Simply, Ethiopian children have the highest odds of experiencing state violence, followed by Somalis, then Burundians, Congolese and South Sudanese.

Hypothesis 2 predicts that girls and boys should be equally likely to experience state violence. The state-violence model (specification 2) refutes this expectation. We find that girls have odds of experiencing state violence that are 71 per cent lower the odds for boys. None of the levels in the age variable emerged as statistically significant in the state-violence model. To summarize: both gender and country of origin determine a child refugee's likelihood of experiencing state violence. Boys are much more likely to experience state violence than girls. Ethiopian and Somali children are targeted more often by state authorities for violence, with Ethiopian children having a disproportionately high likelihood of experiencing this kind of violence.

Turning to the second set of models ((Table 2, specifications 3-5), the first two specifications are interesting as far as the expectations set out in the hypotheses 


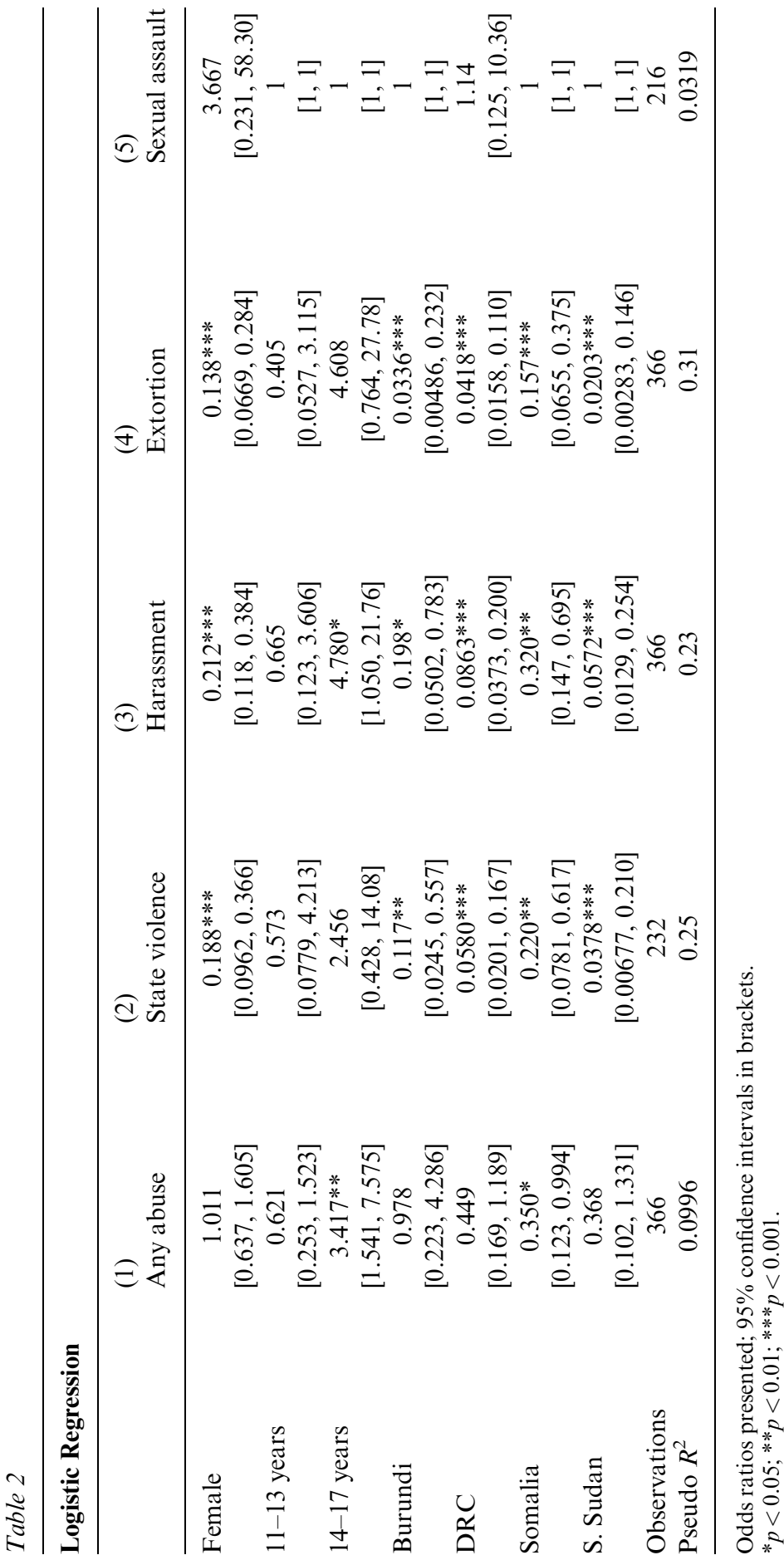


are concerned. We find the odds ratios for five of the seven coefficients in the harassment model to be statistically significant at the 0.05 level. Of these, two are particularly noteworthy. First, the results challenge our expectation that Somali children are more likely to experience harassment by state officials. Indeed, Ethiopian refugees have the highest odds of experiencing harassment. They are followed by Somalis, then Congolese and finally by refugees from South Sudan. Our second hypothesis stipulated that we do not expect a difference between girls and boys with respect to the likelihood of experiencing violence. Contrary to expectation, but in line with the state-violence model, girls have lower odds than boys of experiencing harassment from state officials. Finally, our third hypothesis is confirmed: refugees who are in the 14- to 17year-old age group have odds of being harassed that are 4.78 times the odds of 7- to 11-year-olds.

The extortion model also provides interesting and useful results and roughly mirrors the harassment model. With respect to country of origin (hypothesis 1), Ethiopians have the highest odds of experiencing extortion followed by the Somalis, then the Congolese, the Burundians and the South Sudanese. Each of the levels (countries) in the country-of-origin variable was statistically significant at the 0.05 level. Contrary to the expectation set out in hypothesis 2 , we find that girls have lower odds of having to pay bribes or extortion money to state officials than boys. And, finally, in regard to hypothesis 3 (age), we found no evidence of the effect of age on the likelihood of experiencing extortion.

Regrettably, we are not able to make any inferences from the third model specification: the sexual-assault model. Only four survey respondents reported having been sexually assaulted by a representative of the state. This number is too low to make unbiased inferences.

\section{Conclusions}

Recalling the experiences of 13-year-old Hani recounted at the outset of this article, nearly all child refugees have witnessed and/or experienced horrific levels of violence in their country of origin. Violence is the single most cited precursor to becoming a refugee. However, a child refugee's likelihood of experiencing violence does not dissipate once she arrives in a host country such as Kenya.

Our data reveals that a significant majority (64 per cent) of urban refugee children have experienced violence upon their arrival in Nairobi. Nearly a quarter of respondents (22 per cent) claim to have experienced one or more kinds of violence by state officials. Unsurprisingly to us, Somalis and Ethiopians - visible minorities living in Eastleigh - report having experienced higher levels of state-perpetrated violence compared to refugees hailing from the DRC, Burundi or South Sudan. However, most unexpectedly, our survey reveals that Ethiopian children experience a greater likelihood of state violence than Somalis. This is contrary to the literature and what we have found through extensive fieldwork and qualitative research. The disparity between our survey results and other data requires that we consider one or all of the following: the limitations of survey research on vulnerable 
people and especially children, the size of our sample and the design of the survey instrument. Nevertheless, we are encouraged by the results and the opportunity to work with a unique data set. Further, the limitations above may be offset by future waves of the survey and further research using a more sophisticated mixedmethods approach and should not discount our initial findings.

Both girls and boys claim to have experienced violence at the hands of state officials. However, boys have a much greater likelihood of being targeted for this particular kind of violence. This may have something to do with the site at which state violence occurs. Boys noted that they experienced state violence on the street or at their place of work, whereas girls said they experienced state violence at or near their homes. Considering that state officials are deployed to 'patrol' neighbourhoods on foot, boys in public fora are much more likely to encounter state officials than girls, who are confined to the home.

Finally, our third hypothesis was proved correct; adolescents (aged 14-17) have a greater likelihood of experiencing state violence than younger children. We speculate, in part, that this is due to adolescent refugees (particularly boys) having greater freedom of mobility; many work in the informal economy at odd-jobs outside the home. A refugee child working in a public milieu has a higher chance of encountering security forces on patrol. Additionally, adolescents can pass as young adults. Where a small child might not attract undue attention from the police, a young man will.

These findings are all exploratory and point to the need for further research. Even so, our findings leverage the data at our disposal and indicate areas worthy of additional consideration and theorization.

\section{Acknowledgements}

The authors would like to thank the staff and administration at RefuSHE for their support, generosity and time. An earlier version of this research was presented at the 2019 Canadian Political Science Association Annual Conference - we thank Alana Cattapan for her helpful comments and suggestions.

\section{REFERENCES}

ADAMSON, F. (2006) 'Crossing Borders: International Migration and National Security'. International Security 31(1): 165-199.

AIKEN, S.C., SWANSON, K. and KENNEDY, E. (2014) 'Unaccompanied Migrant Children and Youth: Navigating Relational Borderlands'. In Spyrou, S. and Christou, M. (eds) Children and Borders. London: Palgrave McMillan.

AUKOT, E. (2003) "“It Is Better to Be a Refugee Than a Turkana in Kakuma”: Revisiting the Relationship between Hosts and Refugees in Kenya'. Refuge: Canada's Journal on Refugees, 73-83.

AWUKU, E. (1995) 'Refugee Movements in Africa and the OAU Convention on Refugees'. Journal of African Law 39, 79-86.

BALAKIAN, S. (2016) “"Money Is Your Government”: Refugees, Mobility, and Unstable Documents in Kenya's Operation Usalama Watch'. African Studies Review 59(2): 87-111.

BBC (2009) 'Kenya Drought Worsens Hunger Risk,' BBC, 20 August 2009. http: //news.bbc.co.uk/2/hi/africa/8211753.stm. 


\section{Rosalind Raddatz and Matthew Kerby}

BÖHMELT, T., BOVE, V. and GLEDITSCH, K. S. (2019) 'Blame the Victims? Refugees, State Capacity, and Non-State Actor Violence'. Journal of Peace Research 56(1): 73-87.

BURNS, A. (2010) 'Feeling the Pinch: Kenya, Al-Shabaab, and East Africa's Refugee Crisis'. Refuge 27(1): 5-15.

CLEMENS, M. A. (2017) Violence, Development, and Migration Waves: Evidence from Central American Child Migrant Apprehensions. CDG Paper 459. Washington, DC: Center for Global Development.

DOWTY, A. and LOESCHER, G. (1996) 'Refugee Flows as Grounds for International Action'. International Security 21(1): 43-71.

GEE, S., VARGAS, J. and FOSTER, A. M. (2019) “"The more children you have, the more praise you get from the community": exploring the role of socio cultural context and perceptions of care on maternal and newborn health among Somali refugees in UNHCR supported camps in Kenya'. Conflict and Health 13(1): 11.

GEE, S., VARGAS, J. and FOSTER, A. M. (2019) "“The More Children You Have, the More Praise You Get from the Community": Exploring the Role of Sociocultural Context and Perceptions of Care on Maternal and Newborn Health among Somali Refugees in UNHCR Supported Camps in Kenya'. Conflict and Health 13(1): 11.

GETTLEMAN, J. (2012) Kenya: Somali Refugees Are the Target of a Roundup. New York Times.

HORN, R. I. (2010) 'Responses to Intimate Partner Violence in Kakuma Refugee Camp: Refugee Interactions with Agency Systems'. Social Science \& Medicine 70(1): 160-168.

HUMAN RIGHTS WATCH. (2015) World Report. 2015. Somalia, San Francisco: Human Rights Watch.

HUMAN RIGHTS WATCH (2010) Rights on the Line: Human Rights Watch Work on Abuses against Migrants in 2010. New York: Human Rights Watch.

IM, H., SWAN, L. E. T. and HEATON, L. (2019) 'Polyvictimization and Mental Health Consequences of Female Genital Mutilation/Circumcision (FGM/C) among Somali Refugees in Kenya'. Women \& Health 11: 1-16.

IMMIGRATION AND REFUGEE BOARD OF CANADA(1989) 'Kenya: 1) Was there a wave of Ugandan immigrants coming into Kenya during 1972-1973?2) Treatment of Ugandan workers and illegals in Kenya; 3) How one can obtain citizenship and residence status in Kenya; can a Ugandan living in Kenya for 15 years automatically obtain Kenyan citizenship or residency?, 1 December 1989, KEN3036, KEN3037, https:// www.refworld.org/docid/3ae6ab0833.html (accessed May 2019).

INSTITUT DE RELATIONS INTERNATIONALES ET STRATÉGIQUES (2015) North Eastern Kenya: A Prospective Analysis. Paris: Institut de Relations Internationales et Stratégiques (IRIS), Humanitarian and Development Program.

INTERNAL DISPLACEMENT MONITORING CENTRE (2018) KENYA: Figure Analysis Displacement Related to Conflict and Violence. Geneva: IDMC.

JACOBSEN, K. (1997) 'Refugees' Environmental Impact: The Effect of Patterns of Settlement'. Journal of Refugee Studies 10(1): 19-36.

JAKOBSEN, M., MEYER DEMOTT, M. A., WENTZEL-LARSEN, T. and HEIR, T. (2017) 'The Impact of the Asylum Process on Mental Health: A Longitudinal Study of Unaccompanied Refugee Minors in Norway'. BMJ Open 7(6): e015157.

JENSEN, T. K., SOLHEIM SKAR, A.-M., ANDERSSON, E. S. and SKOGBROTT BIRKELAND, M. (2019) 'Long-Term Mental Health in Unaccompanied Refugee Minors: Pre-and Post-Flight Predictors'. European Child \& Adolescent Psychiatry 28: 1671-1682.

KELES, S., FRIBORG, O., IDSØE, T., SIRIN, S. and OPPEDAL, B. (2018) 'Resilience and Acculturation among Unaccompanied Refugee Minors'. International Journal of Behavioral Development 42(1): 52-63.

KENNEDY, E. (2014) No Childhood Here: Why Central American Children are Fleeing their Homes. Washington, DC: American Immigration Council.

KO, L. K. and PERREIRA, K. M. (2010) 'It Turned My World Upside Down": Latino Youths' Perspectives on Immigration'. Journal of Adolescent Research 25(3): 465-493. 
KUMSSA, A., WILliAMS, J. H., JONES, J. F. and DES MARAIS, E. A. (2014) 'Conflict and Migration: The Case of Somali Refugees in Northeastern Kenya'. Global Social Welfare 1(4): $145-156$.

MAJUMDER, P., VOSTANIS, P., KARIM, K. and O'Reilly, M. (2019) 'Potential Barriers in the Therapeutic Relationship in Unaccompanied Refugee Minors in Mental Health'. Journal of Mental Health 28(4): 372-378.

MASTERS, N. B., WAGNer, A. L., CARlSON, B. F., MUUO, S. W., MUTUA, M. K. and BOULTON, M. L. (2019) 'Childhood Vaccination in Kenya: Socioeconomic Determinants and Disparities among the Somali Ethnic Community'. International Journal of Public Health 64(3): 313-322.

MENJÍVAR, C. and PERREIRA, K. M. (2019) 'Undocumented and Unaccompanied: children of Migration in the European Union and the United States'. Journal of Ethnic and Migration Studies 45(2): 197-217.

MURAYA, J. (2016) 'Kenya: Dadaab Is a Breeding Ground for Terrorists', allAfrica, https://allafrica. com/stories/201605120545.html (accessed May 2019).

O'CALlaghaN, S. and STURGE, G. (2018) Against the odds: Refugee Integration in Kenya. Humanitarian Policy Group (HPG) Working Paper, December 2018, https://www.odi.org/sites/ odi.org.uk/files/resource-documents/12542.pdf (accessed January 2020).

O'HIGGINS, A., OTT, E. M. and SHEA, M. W. (2018) 'What Is the Impact of Placement Type on Educational and Health Outcomes of Unaccompanied Refugee Minors? A Systematic Review of the Evidence'. Clinical Child and Family Psychology Review 21(3): 354-365.

OPE, M., NYOKA, R., UNSHUR, A., OYIER, F. O., MOWLID, S. A., OWINO, B. et al. (2017) 'Evaluation of the Field Performance of ImmunoCard STAT! ${ }^{\circledR}$ Rapid Diagnostic Test for Rotavirus in Dadaab Refugee Camp and at the Kenya-Somalia Border'. The American Journal of Tropical Medicine and Hygiene 96(6): 1302-1306.

OPPEDAL, B., GURIBYE, E. and KROGER, J. (2017) 'Vocational Identity Development among Unaccompanied Refugee Minors'. International Journal of Intercultural Relations 60: 145-159.

PARKER, A. (2002) Hidden in Plain View: Refugees living without Protection in Nairobi and Kampala. Human Rights Watch.

PAVANEllo, S., ELHAWARY, S. and PANTUliano, S. (2010) Hidden and Exposed: Urban Refugees in Nairobi, Kenya. London, Overseas Development Institute.

PLENER, P. L., GROSCHWITZ, R. C., BRAHLER, E., SUKALE, T. and FEGERT, J. M. (2017) 'Unaccompanied Refugee Minors in Germany: Attitudes of the General Population towards a Vulnerable Group'. European Child \& Adolescent Psychiatry 26(6): 733-742.

RICE, X. (2009) 'Almost 4 million Kenyans on food aid as drought deepens,' The Guardian, 18 Sept 2009. https://www.theguardian.com/world/2009/sep/17/kenya-drought-cattle-deaths.

SAVUN, B. and GINESTE, C. (2019) 'From Protection to Persecution: Threat Environment and Refugee Scapegoating'. Journal of Peace Research 56(1): 88-102.

SCHARRER, T. (2018) 'Ambiguous Citizens": Kenyan Somalis and the Question of Belonging'. Journal of Eastern African Studies 12(3): 494-513.

SIERAU, S., GLAESMER, H., KLUCKEN, T. and STALDER, T. (2019) 'Hair Cortisol, Lifetime Traumatic Experiences and Psychopathology in Unaccompanied Refugee Minors'. Psychoneuroendocrinology 104: 191-194.

SOHNS, A. (2016) 'Somali Refugees: Between Shelter and Discrimination', BTI Project, https://our world.unu.edu/en/somali-refugees-between-shelter-and-discrimination (accessed January 2020).

SWANSON, K. and TORRES, R. M. (2016) 'Child Migration and Transnationalized Violence in Central and North America'. Journal of Latin American Geography 15(3): $23-48$.

SY, A. (ed.) (2017) Foresight Africa: Top Priorities for the Continent in 2017. Africa Growth Initiative at Brookings, https://www.brookings.edu/wp-content/uploads/2017/01/global_20170109_fore sight_africa.pdf (accessed July 2019).

THE STAR (2014) '6100 Police and Soldiers Crackdown on Eastleigh', https://diasporamessenger. com/2014/04/6100-police-and-soldiers-deployed-in-eastleigh/ (accessed May 2019). 


\section{Rosalind Raddatz and Matthew Kerby}

TRANG T. and LAU W. (2002). Psychological Well Being of Child and Adolescent Refugee and Asylum Seekers: Overview of Major Research Findings of the Past Ten Years. Sydney: National Inquiry into Children in Immigration Detention, Human Rights and Equal Opportunity Commission.

UK AMNESTY INTERNATIONAL. (2018). Syria. New York. Amnesty International.

UNHCR (2014) Kenya Comprehensive Refugee Programme 2014. Geneva: UNHCR.

UNHCR (2017a) 'Kenya Factsheet, June 2017', https://www.unhcr.org/ke/wp-content/uploads/sites/ 2/2017/07/Kenya-Operation-Factsheet-June-2017-.pdf (accessed May 2019).

UNHCR (2017b) Operational Statistics. Geneva: UNHCR.

UNITED NATIONS HIGH COMMISSIONER FOR REFUGEES (2012) The State of the World's Refugees 2012: in Search of Solidarity. Oxford: Oxford University Press.

UNITED NATIONS HIGH COMMISSIONER FOR REFUGEES (2016). Refugees in the Horn of Africa: Somali Displacement Crisis.

YUSEF, M. (2014) 'Kenyan Police Dogged by Extortion Charges: Somali Refugees Arrested in Counter-Terror Crackdown Forced to Bribe Police Despite Having Proper Identification Papers', Al-Jazeera, https://www.aljazeera.com/news/africa/2014/08/kenyan-police-dogged-extortioncharges-20148513110560888.html (accessed January 2020).

WAHLSTRÖM SMITH, A. (2018) “"Hiding in Plain Sight”: Daily Strategies and Fear Management among Undocumented Refugee Children in Sweden'. Journal of Refugee Studies 31(4): 588-604.

WONG, T. K. (2014) Statistical Analysis Shows that Violence, Not Deferred Action, Is Behind the Surge of Unaccompanied Children Crossing the Border. Washington, DC: Center for American Progress. 